\title{
COMO OS EMPREENDEDORES TRABALHAM: UMA LEITURA PSICODINÂMICA DA ORGANIZAÇÃO DO TRABALHO DE UM GRUPO DE EMPREENDEDORES
}

Edward Humberto Guimarães Júnior ${ }^{1}$

${ }^{1}$ Universidade Federal de Goiás 


\title{
COMO OS EMPREENDEDORES TRABALHAM: UMA LEITURA PSICODINÂMICA DA ORGANIZAÇÃO DO TRABALHO DE UM GRUPO DE EMPREENDEDORES
}

\begin{abstract}
Resumo: A ação empreendedora vem sendo bastante valorizada no atual modelo econômico, político e social, porém, poucos estudos consideram os empreendedores na condição de trabalhadores. Em razão desta situação, o objetivo deste estudo é descrever a organização do trabalho dos empreendedores, tendo como abordagem teórico-metodológica a Psicodinâmica do Trabalho. Foram realizadas quatro sessões coletivas com um grupo de oito empreendedores e tendo como instrumento de coleta de dados um questionário semiestruturado. As sessões foram gravadas e depois analisadas utilizando a técnica de Análise de Conteúdo. Pode-se constatar que a forma de organização do trabalho do empreendedor se diferencia da maioria dos trabalhadores, sendo caracterizada por uma rotina de imprevistos e preparação. Em geral, os empreendedores possuem uma agenda diária cheia de compromissos, o que remete a uma carga de trabalho intensa. Contudo, eles possuem o poder de fazer modificações na organização do seu trabalho, proporcionando maior liberdade no cotidiano laboral.
\end{abstract}

Palavras-chave: Empreendedorismo. Empreendedor. Psicodinâmica do Trabalho. Organização do Trabalho.

\section{Introdução}

O novo modelo de economia de mercado que surgiu na pós-modernidade, baseado no consenso de Washington de 1989, também chamado de neoliberalismo e amplamente adotado como a solução para a crise capitalista, incentivou a criação de novos modelos de gestão nas empresas, orientados para maximização dos resultados operacionais e para um consumismo sem precedentes. Tal modelo tem deixado em segundo plano a saúde física e mental dos trabalhadores e agravado os problemas do mundo do trabalho, marcado por injustiças e pela manipulação do corpo e da subjetividade dos trabalhadores.

A saúde mental dos trabalhadores passa a ser um tema relevante na modernidade, atraindo a atenção de clínicos, médicos do trabalho, psicólogos e administradores interessados em compreender mais profundamente as relações entre a saúde do trabalhador e a organização do trabalho. Neste panorama o presente estudo buscou compreender a organização do trabalho 
dos empreendedores, cuja atuação, segundo Filion (2000), requer habilidades de mobilizar e comandar os meios de produção, bem como de criar estruturas organizacionais eficientes para alcançar um objetivo econômico, assumindo as responsabilidades dos riscos incorridos de suas ações.

Para Chanlat (1995), a carreira empreendedora é constitutiva da sociedade capitalista neoliberal e de sua ideologia de sucesso individual. Segundo o autor, fatores como as dificuldades do setor público, a crise da previdência, as dispensas maciças em certos setores produtivos, a precarização cada vez maior do trabalho e a concorrência internacional têm empurrado os governos, as empresas e as sociedades para valorizarem esse tipo de carreira.

Schmidt e Bohnenberger (2009) apontam para uma forte relação entre as características do perfil empreendedor e o desempenho organizacional. Para os autores o desempenho organizacional está relacionado ao perfil empreendedor que, por sua vez, se aproxima da figura do líder e da disposição para assumir riscos. Autores como Eckert, Meca, Biasio e Coraiola (2011) em seus estudos conceituais apontam que a Psicologia do Trabalho pode contribuir para o desenvolvimento de um ambiente que propicie, por exemplo, o intraempreendedorismo através de ações desenvolvidas pelos indivíduos em seu próprio ambiente de trabalho. Neste sentido, a orientação psicodinâmica do trabalho pode nos dar maior clareza sobre como atuam os empreendedores e sobre como a sua atuação pode afetar as outras pessoas no mundo do trabalho, podendo trazer reflexões que contribuam para a melhoria das práticas de gestão.

\section{O Olhar da Psicodinâmica do Trabalho sobre a Organização do Trabalho}

Os avanços nos estudos em Psicologia do Trabalho na atualidade teve um importante marco com o surgimento da Psicodinâmica do Trabalho como corrente de estudo teórica e metodológica. Criada pelo psiquiatra francês Christophe Dejours na década de 1980, a Psicodinâmica do Trabalho está voltada para o estudo da relação trabalho e saúde, com um forte viés na contraditória normalidade dos trabalhadores em constante luta contra o sofrimento psíquico em meio à conjuntura negativa das situações de trabalho, dada a precariedade das condições de trabalho e a opressão exercida pela hierarquia organizacional, além das contradições, incompatibilidades e conflitos resultantes das relações de trabalho, com notáveis reflexos sobre o corpo e o psiquismo de homens e mulheres em situação laboral.

Para a Psicodinâmica do Trabalho, trabalhar significa o engajamento da subjetividade e dos desejos individuais num mundo hierarquizado, ordenado e coercitivo, perpassado pela dominação do corpo e da mente, resultando em sérias consequências para a saúde do trabalhador. O trabalho assume, então, uma posição central e de grande complexidade sobre o processo dinâmico de formação da identidade e da manutenção da saúde psíquica, em meio às condições e relações sociais de trabalho.

Dejours (2004) conceitua a organização do trabalho como a divisão do trabalho, o conteúdo das tarefas, o sistema hierárquico, as modalidades de comando, as relações de poder e as questões de responsabilidade. $\mathrm{O}$ autor esclarece que, enquanto as condições de trabalho prejudicam a saúde do corpo do trabalhador, a organização do trabalho atua no nível do funcionamento psíquico. 
Historicamente, a organização do trabalho é marcada pela busca de produtividade e economicidade instituída pelos princípios de Taylor na década de 1910, que mobilizou a escola da administração científica do trabalho, estabelecendo como princípios: a divisão do trabalho em atividades específicas e simplificadas, o controle do tempo de execução das atividades e dos movimentos físicos dos trabalhadores, o planejamento do sistema produtivo incumbido apenas às esferas gerenciais e anulando qualquer intervenção operária nesse processo, bem como a constituição de uma estrutura hierarquizada de comando e controle a fim de manter a disciplina no trabalho.

Mais adiante, no período pós-guerra, o modelo de gestão japonês, conhecido como produção enxuta, trouxe novas contribuições para a organização do trabalho. Como principais exemplos das contribuições deste modelo de gestão estão os trabalhadores multifuncionais e mais escolarizados, aptos a realizarem diversas operações e uma maior preocupação da hierarquia com a segurança dos trabalhadores e com a redução de riscos de acidentes no trabalho.

Mudanças estruturais ocorridas nos últimos anos, em decorrência do processo de reestruturação produtiva, influenciados pelo modelo capitalista neoliberalista, fortemente caracterizado pela competitividade e disputas por mercados, impulsionaram novas adaptações aos modelos de organização do trabalho. Porém, o que podemos constatar é que ainda estamos longe de um modelo de organização do trabalho consolidado e que privilegie a saúde do trabalhador, em especial no que tange à saúde mental.

Dejours (1949) constatou em suas investigações que existem distorções significativas entre a organização do trabalho concebida pela hierarquia, denominada pelo autor como "trabalho prescrito", e o trabalho que é realizado na prática, denominado por ele como o "trabalho real" e que, por sua vez, envolve o saber fazer do trabalho, sendo este de domínio exclusivo do trabalhador para dar conta das diversidades advindas de suas atividades laborais e cumprir com os objetivos e metas de produtividade. Tal constatação revela a existência do confronto do trabalhador com as dificuldades reais para a realização do trabalho, dada a existência de discrepâncias entre o que é prescrito pelas diretrizes, normas e métodos formalizados pela hierarquia, e o que é real, produto da experiência, da criatividade e do saber fazer do trabalhador, ou seja, a realidade concreta das situações vivenciadas pelo trabalhador.

Segundo Dejours (1999), o real do trabalho não é somente o real do mundo objetivo, ele é, também, o real do mundo social que envolve a resistência a ser dominada, sendo, portanto, uma experiência individual no que se refere ao desenvolvimento da inteligência e da subjetividade do trabalhador. Para o autor o real do trabalho confronta o sujeito ao fracasso, onde surge um sentimento de impotência, de irritação, de decepção ou de esmorecimento. A impossibilidade de execução do trabalho real resulta em uma situação desagradável e conflituosa que mobiliza a subjetividade do trabalhador de um modo afetivo levando os trabalhadores a fazerem uso de estratégias defensivas.

Para Dejours (1999), as estratégias defensivas são as reações construídas pelos trabalhadores para o enfrentamento e a proteção contra as situações de risco e o consequente sofrimento no trabalho. O autor explica que, para poder suportar o medo e as pressões inerentes ao trabalho, são construídas estratégias decorrentes dessas pressões, sendo estas importantes para manter o equilíbrio psíquico e favorecer a adaptação do sujeito às situações penosas do trabalho.

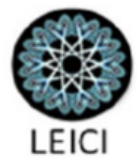


No Brasil, as pesquisas em Psicodinâmica do Trabalho apresentaram avanços significativos nas últimas décadas, abarcando um leque variado de profissões, em especial nas áreas da saúde, educação, bancário e serviços públicos. Encontram-se, também, estudos relacionados a serviços de teleatendimento, catadores de lixo, operários da construção civil, artistas, escritores literários e executivos.

\section{Procedimento Metodológico}

Este artigo tem como objetivo descrever a organização do trabalho dos empreendedores a partir da compreensão das suas vivências concretas de trabalho. Trata-se de um estudo de caráter descritivo exploratório com abordagem qualitativa e utilizando dados empíricos primários, voltado para a compreensão dos processos subjetivos e intersubjetivos mobilizados por um grupo de empreendedores e expressos pela fala em um espaço de discussão coletivo. Como corrente de estudo teórico-metodológica baseou-se na Psicodinâmica do Trabalho, privilegiando as seguintes categorias: conteúdo das tarefas, normas e controles, sobrecarga de trabalho, relações profissionais, comunicação e modo de gestão.

O coletivo de pesquisa foi formado por 8 (oito) empreendedores formais bem sucedidos que iniciaram os seus respectivos negócios, sendo atuantes na gestão dos mesmos e que se dispuseram livremente a participarem da pesquisa. Como estratégias de aproximação do coletivo de pesquisa, conforme proposto por Mendes e Araújo (2011), o pesquisador participou de encontros formais e informais, dentro e fora dos seus respectivos ambientes de trabalho, que ocorreram previamente à construção e a análise da demanda. Pode-se constatar, desta forma, que embora pertençam a organizações de trabalho distintas, as situações e os contextos de trabalho vivenciados por cada um dos empreendedores se assemelham.

Todos os participantes aceitaram participar voluntariamente da pesquisa, concordaram que as sessões fossem gravadas, leram e assinaram o termo de esclarecimento e consentimento para participação como entrevistado desta pesquisa. Para efeito da preservação da identidade dos trabalhadores os seus nomes foram substituídos por códigos iniciados com a letra "E". A seguir são apresentados os perfis de cada um dos participantes. 
Quadro 1: Perfil dos participantes do coletivo de pesquisa

\section{Participante E-1:}

O participante E-1 tem 46 anos e é casado, possui formação superior em Odontologia e titulação de mestre. Atua como empreendedor no segmento de clínica radiológica há 17 anos, sendo proprietário de duas empresas e possuindo 3 sócios e 7 funcionários. Atuou em empresa privada durante 17 anos como professor. Optou pela carreira de empreendedor primeiramente por oportunidade, mas também por necessidade.

\section{Participante E-2:}

O participante E-2 tem 32 anos e é casado, possui formação superior em Tecnologia em Gestão Comercial. Atua como empreendedor no segmento de cursos na área de investimentos há 2 anos, sendo proprietário de uma empresa de treinamento e possuindo 1 sócio e 1 funcionário celetista. Os demais funcionários que possui são professores contratados como prestadores de serviços. Atuou em empresa privada de grande porte durante 10 anos. Optou pela carreira de empreendedor por oportunidade.

\section{Participante E-3:}

O participante E-3 tem 40 anos e é divorciado, possui formação superior em Arquitetura. Atua como empreendedor no segmento gráfico há 2 anos, sendo proprietário de duas empresas, possui 2 sócios e 5 funcionários. Atuou em empresa privada multinacional durante 20 anos. Optou pela carreira de empreendedor por oportunidade.

\section{Participante E-4:}

O participante E-4 tem 39 anos e é casado, possui formação superior em Engenharia Civil e Engenharia Eletrônica. Atua como empreendedor nos segmentos de prestação de serviços de limpeza, vestuário e perfumaria há 8 anos, sendo proprietário de 3 empresas e possuindo 3 sócios e 63 funcionários. Atuou em empresa privada de grande porte durante 10 anos. Optou pela carreira de empreendedor primeiramente por oportunidade, mas também por necessidade.

\section{Participante E-5:}

O participante E-5 tem 31 anos e é solteiro, possui formação superior em Turismo e Hotelaria. Atua como empreendedor no segmento de restaurante há 6 anos, sendo proprietário de três empresas e possuindo 3 sócios e 60 funcionários. Atuou em empresa privada multinacional durante 3 anos. Optou pela carreira de empreendedor por oportunidade e vontade de crescimento profissional.

\section{Participante E-6:}

O participante E-6 tem 49 anos e é casado, possui formação superior em Economia e MBA em Gestão Empresarial, Liderança e Desenvolvimento Organizacional. Atua como empreendedor no segmento de consultoria organizacional há 18 anos, sendo proprietário de 1 empresa, não possui sócio e possui 2 funcionários. Atuou em empresa privada de grande porte nos setores bancário, industrial e comercial. Optou pela carreira de empreendedor por oportunidade.

\section{Participante E-7:}

O participante E-7 tem 52 anos e é casado, possui formação superior em Administração e Mestrado em Gestão de Agronegócios. Atua como empreendedor no segmento de tecnologia de gestão e construção civil há 25 anos, sendo proprietário de duas empresas no setor de tecnologia de gestão possuindo 4 sócios e 5 funcionários. Também é sócio de uma empresa S/A de construção civil com 60 associados. Atuou em empresa do setor público durante 7 anos. Optou pela carreira de empreendedor por oportunidade e por sentir vontade de constituir o seu próprio negócio.

\section{Participante E-8:}

O participante E-8 tem 62 anos e é casado, possui formação superior em Administração. Atua como empreendedor no segmento de cursos de formação de líderes há 20 anos, sendo proprietário de uma empresa de treinamento e possuindo 1 sócio e 4 funcionários. Atuou em empresa privada multinacional durante 10 anos. Optou pela carreira de empreendedor por oportunidade e por se sentir descontente com o emprego anterior.

As sessões foram previamente agendadas considerando a disponibilidade dos trabalhadores. No total foram realizadas 4 (quatro) sessões coletivas com o grupo de 
empreendedores, com duração total aproximada de 12 (doze) horas. As sessões foram conduzidas de forma ética de modo a favorecer positivamente os laços de confiança, solidariedade e afetividade entre os participantes, tendo sido realizadas no local de trabalho de um dos participantes, onde se obteve condições adequadas para que a pesquisa pudesse ser realizada. Todas as sessões foram gravadas em áudio e vídeo e depois transcritas para compor o corpus de pesquisa, preservando as falas e expressões dos participantes durante as sessões.

Para a condução das sessões foi utilizado um roteiro com perguntas semiestruturadas elaboradas com base nas seguintes categorias da Psicodinâmica do Trabalho: conteúdo das tarefas, normas e controles, sobrecarga de trabalho, relações profissionais, comunicação e modo de gestão. Algumas adaptações nas perguntas foram realizadas no decorrer das sessões para ajustá-las ao diálogo dos participantes, dando ênfase aos aspectos de maior relevância que emergiram durante o diálogo.

O material coletado nas gravações, compreendendo as falas e expressões dos empreendedores, foi transcrito e posteriormente analisado usando a análise de conteúdo de Bardin (1977) como técnica de análise apoiada nos pressupostos da Psicodinâmica do Trabalho. Alguns trechos das falas dos trabalhadores foram selecionados e apresentados durante o capítulo de análise e discussão dos resultados deste estudo, como forma de evidenciar as análises feitas a partir dos dados coletados durante as sessões com os trabalhadores.

\section{Resultados e Análises}

Os empreendedores alegam não terem uma rotina de trabalho definida, sendo o seu dia de trabalho marcado por surpresas, o que requer uma preparação contínua e diária. Mesmo que tentem planejar o seu trabalho, sempre tem um imprevisto que acaba atrapalhando a programação. Em geral, eles possuem uma agenda diária cheia de compromissos, porém possuem o poder de fazer modificações nas suas atividades e nos seus horários, assim, a rotina acaba sendo de preparação. Os empreendedores reconhecem que no seu trabalho nem sempre o que é previsto é o real.

\footnotetext{
Tenho uma rotina de surpresas todos os dias, então acho que minha rotina acaba sendo de preparação, todo dia é dia de preparação (E-5).

Rotina eu acho que a gente não tem. Por mais que a gente tenta planejar, planeja, planeja, planeja, sempre tem um imprevisto que acaba atrapalhando um ou outro planejamento (E-2).
}

De Vries (1985) explica que os empreendedores não se enquadram em trabalhos repetitivos e rotineiros, sendo caracterizados como sujeitos orientados para a realização e que gostam de assumir responsabilidades. Assim, mesmo vivenciando uma rotina de incertezas e tendo que lidar com o medo do insucesso, o que remete a fontes de angústia e sofrimento, os empreendedores parecem compensar esse fato com o sentimento de liberdade ao poder planejar e flexibilizar as suas atividades e horários.

Os empreendedores têm o Governo como um dificultador do seu trabalho, requerendo que eles desprendam tempo e esforço para compreender e cumprir a burocracia imposta. $\mathrm{O}$
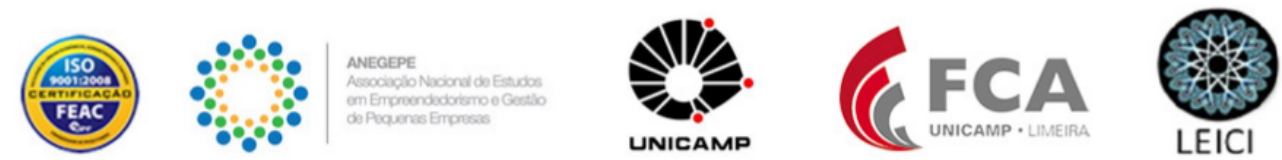
Governo é tido pelos empreendedores como um "patrão", "maior sócio" e até "covarde", que recebe os impostos, mas não dá o retorno esperado pelo que é pago, e que, inoportunamente, sujeita os empreendedores à fiscalização "propineira" e despreparada.

[...] Vou lá no passado quando a gente vai abrir uma empresa, não só no dia a dia, quando a gente abre a empresa tem a questão burocrática, tributação, parece que tem uma mão não deixando você caminhar, emperrando (E-4).

O governo é o seu patrão, te coloca pra trabalhar e só quer o bom, "o dinheiro" (E$5)$.

Os empreendedores alegam que mesmo agindo honestamente, eles estão sujeitos à fiscalização "propineira" e despreparada, ocasionando um sentimento de inconformismo ao terem que provar que não estão fazendo errado.

Outra cosia que incomoda é a fiscalização. Vigilância sanitária é uma loucura por que geralmente se o cara vem fiscalizar o restaurante ele não entende nada de restaurante, pelo menos na experiência que eu tenho a lei serve pra ser cumprida, mas existem algumas coisas que são específicas de cada profissão e o fiscal não sabe relevar e interpretar determinada situação (E-1).

A burocracia imposta pelo Governo pode ser comparada, no contexto da Psicodinâmica do Trabalho, com o que Dejours (2004) chamou de "trabalho prescrito". Para o autor, o trabalho prescrito constitui-se em normas, regras e procedimentos impostos pela organização do trabalho ao trabalhador. Assim, para o empreendedor, o Governo assume o papel da hierarquia e que, por sua vez, possui o poder de estabelecer as regras e de manter o controle, além de aplicar penalidades caso se constate o descumprimento das leis e normas instituídas.

Outra questão relacionada ao Governo que dificulta o trabalho dos empreendedores foi identificada nos estudos de Nassif, Nassif, Piscopo e Lima (2015). Em sua pesquisa os empreendedores apontam a precariedade da infraestrutura de transporte do país, o que dificulta e encarece o transporte de produtos, comprometendo o atendimento dos clientes com rapidez, qualidade e segurança, obrigando os empreendedores a realizarem mais investimentos em transporte, armazenamento e seguro dos produtos. Tal questão não foi relatada pelos empreendedores que participaram deste coletivo de pesquisa, contudo corrobora com o objetivo deste estudo.

As questões relacionadas ao mercado de mão de obra também afetam o trabalho dos empreendedores como: falta de mão de obra, má qualificação, alta rotatividade, baixo nível cultural dos funcionários entre outras questões específicas de cada negócio. Assim, obter mão de obra qualificada, que compreenda a visão do empreendedor e estejam comprometidos com o negócio é uma grande dificuldade para os empreendedores e que lhes causam irritação.

A rotatividade é bastante alta, principalmente quando você está começando, porque no começo da empresa geralmente é um pouco bagunçado, as pessoas não querem fazer nenhuma aposta e os que fazem são um pouco aventureiros, procuram abertura de empresa pra poder barganhar alguma coisa a mais (E-5).

Eu sofro muito por mão de obra qualificada [...] (E-4). 
Os empreendedores estão sujeitos ao fracasso de suas ações e lidam com adversidades e incertezas cotidianamente, por exemplo, eles citam os períodos sazonais em que as vendas são baixas e a margem de lucro é reduzida, assim como os períodos de entressafra que comprometem o fornecimento de matéria-prima.

Então a gente enfrenta alguns problemas tipo a safra, a gente tem alguns períodos de entressafra, igual a carne, que agora costuma aumentar e eu não posso alterar o cardápio, se a carne subiu vinte por cento eu não posso de hoje pra amanhã aumentar vinte por cento no cardápio (E-5).

O trabalho do empreendedor, segundo Frese (2009), compreende em lidar com exigências diversas e geralmente conflitantes que o coloca numa situação de constante sensação de opressão pelas exigências internas e externas da organização do trabalho, tendo que ser capaz de tomar decisões com rapidez, cumprir metas de curto e longo prazo, além de estar sujeito a lidar com erros, reveses e barreiras. As constatações do autor também indicam que os empreendedores são realizadores ativos e que fazem uso de planos, conscientes ou não, para poderem atuar em ambientes que envolvam altos níveis de riscos e incertezas.

Assim, os empreendedores estão sujeitos ao fracasso, tendo que serem geridos e superados por eles próprios, tornando o seu trabalho ainda mais complexo. $\mathrm{O}$ estudo realizado por Minello, Scherer, Perlin, Alves e Huezo (2011), aponta erros cometidos por empreendedores que os levaram ao fracasso como: excesso de autoconfiança, falta de conhecimento, problemas com os sócios, falta de apoio externo e não aprender com os próprios erros. Os empreendedores pesquisados pelos autores vivenciaram o insucesso nos negócios levando à descontinuidade do negócio.

Para Scherer e Minello (2014) a característica do comportamento do empreendedor em correr riscos, remete à sua capacidade de enfrentamento e resiliência diante do insucesso. Os autores identificaram em seus estudos que os empreendedores se engajam em um processo de aprendizagem, que, por sua vez, se constitui em uma forma de racionalização para lidar com as situações de insucesso a que estão sujeitos em decorrência de seu trabalho.

Os empreendedores buscam estabelecer planos e mecanismos de controles que os norteiam para o alcance das metas e dos padrões de qualidade dos produtos e serviços que entregam aos clientes. Contudo, isso se dá de forma nem sempre formalizada e reconhecem que, por mais que tentem fazer do jeito deles, eles nem sempre conseguem e reconhecem que, por mais que tentem fazer um planejamento, nem sempre conseguem obter êxito, o que requer certa resiliência para continuarem realizando o trabalho.

Vivo no fio da navalha o tempo todo, faz vinte anos sem eu saber se no mês que vem vai ter dinheiro, mas graças a Deus todo mês eu tenho, esse é o lado gostoso, ao mesmo tempo que é estressante e muito divertido, é por que você pega esse pique. Se não der, dá sim (E-8).

A capacidade dos empreendedores em fazer planos, também foi identificada pelos autores Paiva Junior (2004), Guimarães e Siqueira (2010) e Machado (1999). Para os autores, 
o empreendedor está fortemente relacionado à sua capacidade de planejamento, organização e liderança.

Os empreendedores consideram as exigências dos clientes como compromissos a serem cumpridos sem o qual não é possível obterem sucesso no seu trabalho. Reconhecem que dependem do cliente e necessitam estar sempre negociando e renegociando o tempo todo e, com isso, sentem que não trabalham com total liberdade, mas acreditam ter maior liberdade para organizar a empresa do seu jeito.

A cobrança do cliente é muito grande, você tem que estar sempre negociando, renegociando o tempo todo, então não trabalhamos com liberdade (E-6).

O relacionamento com os clientes é marcado pelo equilíbrio entre as exigências dos clientes e a capacidade de entrega da empresa. Porém, nem sempre a empresa consegue entregar o que o cliente quer, apesar de todo o esforço por parte do empreendedor para tentar manter o padrão dos produtos e serviços oferecidos e satisfazer o cliente.

A gente tem que ter um limite de até aonde vai o direito que o cliente tem e até onde a empresa pode ir, porque se a gente for atender tudo que o cliente quer, a gente quebra, porque as pessoas sempre querem o mais barato, o mais rápido pra ontem e melhor, o melhor a gente consegue, mas aí nem sempre todas as coisas juntas ao mesmo tempo (E-1).

Os empreendedores, além dos clientes, também se sentem constantemente cobrados pelos seus funcionários e relacionam o desempenho do funcionário ao seu próprio desempenho. Concluem que não trabalham com liberdade devido às exigências não só dos clientes, mas também dos funcionários.

Eu me sinto cobrado tanto dos clientes quanto dos funcionários, eles cobram e acabam exigindo. Se você está comprometido, o funcionário também vai estar, então os funcionários também cobram assim como os clientes (E-5).

Engraçado isso, mas é verdade, no meu caso é assim também e mais, diria que a cobrança dos funcionários é mais natural e está interagindo o tempo todo

(E-6).

Os empreendedores se consideram autogestores e multifuncionais, não se limitando a uma jornada de trabalho, como ocorre com os demais funcionários. Constantemente levam trabalho para casa e realizam atividades inclusive aos finais de semana. Alegam trabalhar mais que os próprios funcionários, contudo eles não se queixam de se sentirem sobrecarregados e não reclamam do trabalho como eles observam que os seus funcionários fazem. Apesar de quererem "abraçar tudo" reconhecem que o acúmulo de atividades dificulta a realização de ações que julgam importantes.

Durmo pensando no trabalho (E-7).

$\mathrm{Eu}$ acho que o empreendedor trabalha mais do que um funcionário. Por ser multifuncional, então você acaba perdendo tempo, tendo dificuldade de realizar algumas coisas. Você acumula outras coisas que talvez fossem mais simples de 
resolver e "poxa" não é nada e eu não estou dando conta de resolver e estou tentando reverter essa situação (E-5).

A realização de multitarefas também foi identificada nos relatos dos empreendedores no estudo de Ésther, Rodrigues e Freire (2012) sobre a identidade social dos empreendedores. No referido estudo os empreendedores relatam ser o "faz tudo" atuando em atividades diversas que vão do operacional à gestão da organização, enfatizando aspectos relativos ao trabalho gerencial no sentido dos empreendedores se dedicarem mais com a resolução dos problemas que surgem no dia a dia do seu trabalho.

Os empreendedores reconhecem que dependem do desempenho dos seus funcionários para alcançarem os seus objetivos, porém muitas vezes enfrentam uma incompatibilidade entre os interesses dos funcionários e os seus próprios interesses, fazendo com que o empreendedor tenha que fazer uso de mecanismos de controle para manterem os funcionários produtivos. Em alguns casos acabam realizando a tarefa que não foi cumprida pelo funcionário, o que lhes causam dificuldades. Alegam que trabalhar com pessoas é um desafio a ser superado e que, por isso, nem sempre conseguem fazer do jeito que eles querem. Acreditam que se os funcionários não se sentirem e agirem como donos da empresa eles não conseguem prosperar. Para o empreendedor mais jovem do coletivo de pesquisa o fato de ser jovem é um agravante para conseguir o respeito da equipe.

O meu próprio desempenho como empresário é também o desempenho da minha equipe, então, assim, na realização das tarefas, encontro dificuldades tanto em mim quanto encontro dificuldades na equipe (E-6).

Os empreendedores lidam com situações conflituosas resultantes de direitos dos empregados que eles próprios não têm, como é o caso do seguro desemprego, do registro na carteira de trabalho e das obrigações trabalhistas. Acrescentam que as leis trabalhistas são ultrapassadas e que acabam por atrapalhar o seu trabalho. Em muitos casos eles percebem que os funcionários utilizam de má-fé e ainda assim são amparados pelas leis trabalhistas. Os empreendedores acabam se sentindo reféns dos próprios funcionários e sofrendo as consequências.

\footnotetext{
Me sinto refém do funcionário também, ele pede pra você mandar ele embora e se eu mandar eu sou o prejudicado, se eu não mandar ele vai me prejudicar mais ainda, vai comprometer minha empresa. Essa semana mesmo eu tive um caso de um chefe de cozinha que estava saindo, saiu e ai ele pegou e passou por um funcionário 'vou sair pra resolver um negócio' ai ele colocou sal no prato, muito sal mesmo pra prejudicar o restaurante, então se você não faz o que ele quer piora sua situação, então eu assumo o prejuízo, você é o certo eu sou o errado, então sempre fica essa situação. O duro é isso, como que vai provar que ele fez de má-fé? (E-5).

Tem essa também, mesmo quando quer sair fica fazendo corpo mole esperando você mandar ele embora (E-2).
}

Situações conflituosas com os funcionários, assim como com os clientes, vivenciadas pelos empreendedores também foram identificados no estudo de Ésther, Rodrigues e Freire 
(2012). Neste estudo os empreendedores alegam existirem funcionários desonestos na organização que acabam dificultando o seu trabalho.

Os empreendedores buscam se relacionar de forma amigável com os seus sócios para manterem o equilíbrio no trabalho. Alegam que é necessário combinar e dividir as tarefas entre os sócios para que a sociedade possa prosperar, porém relatam que nem sempre ter um sócio ajuda no seu trabalho. Consideram que as relações com sócios, assim como com os clientes, funcionários, fornecedores e parceiros contribuem para o seu amadurecimento, fazendo com que eles aprendam a escutar mais e se tornem mais flexíveis.

Voltando ao sócio que eu tenho, tem que ter transparência e combinar sua função, essa é minha função e essa você tem que fazer, é sua função, senão gera um conflito $(\mathrm{E}-1)$.

A relação conflituosa com os sócios, considerando o processo de tomada de decisões por parte dos empreendedores, também foi identificada nos estudos de Silva, Fonseca e Araújo (2015). Neste estudo os empreendedores relatam a importância de uma segunda opinião por parte dos sócios para auxiliar na tomada de decisão, porém muitas vezes as diferenças de opiniões dos sócios faz com que a tomada de decisão se torne mais difícil.

Para Dejours (2010), trabalhar é uma relação social que envolve o confronto entre a subjetividade e o coletivo de trabalho, ou seja, a intersubjetividade e que resulta na mobilização das relações de afeto. As relações com os funcionários e sócios, se bem sucedidas, permitem ao empreendedor colocar em prática os seus planos organizacionais. Deste modo, o sucesso do empreendedor depende, dentre outras questões, da qualidade do relacionamento que consegue manter com os seus funcionários e sócios.

Embora pouco citado pelos empreendedores, a família e os amigos servem de apoio para superar os momentos difíceis e até para ajudar no trabalho. "Se não tiver cooperação de amigo e família não tem como, isso independe se é empresa ou não, é relação humana" (E-1).

Os empreendedores necessitam comunicar constantemente com sua equipe para transmitir metas, definir prioridades, orientar na execução das tarefas, resolver problemas e debater questões da empresa. Consideram que a comunicação é muito importante para o andamento dos trabalhos e procuram facilitar o processo se colocando a disposição das suas equipes em tempo integral, seja pessoalmente ou por meios eletrônicos. As reuniões, treinamentos e os meios eletrônicos são os principais mecanismos de comunicação direta que são utilizados por eles.

Gosto de reunir minha equipe segunda de manhã para definir as prioridades. Às vezes também requer debate pra ver se a pessoa vai construir aquilo ali, às vezes cinco minutinhos de palavras à gente encurta muita coisa (E-6).

Os empreendedores alegam sentirem dificuldades em transmitir o seu pensamento e fazer com que a equipe entenda a mensagem que eles estão tentando transmitir. Atribuem o problema à diferença cultural dos funcionários e à falta de tempo para fazer a comunicação correta de modo que os funcionários entendam o que eles querem. 
A gente vê a coisa pronta, e às vezes traduzir isso pra eles, exige da gente um cuidado, tempo, que nem sempre a gente tem esse tempo pra dedicar, tempo que precisa pra fazer a comunicação correta (E-6).

Os empreendedores se sentem despreparados para lidarem com a organização do trabalho e atribuem o problema às instituições de ensino que, segundo eles, não fornecem a base correta para que possam desenvolver melhor o seu trabalho. Tendem a serem centralizadores por possuírem dificuldades em delegar tarefas e em confiar nos funcionários, ficando sobrecarregados com atividades operacionais e acumulando mais estresse. "Eu acho que falta preparação do empresário, está um pouco na forma que a gente aprende na escola, a escola não te dá uma preparação pra você ser o que você quer" (E-5).

Os mesmos demonstraram não conhecerem com clareza qual é o seu estilo de gestão e tendem a serem perfeccionistas, centralizadores e individualistas. Contudo, os empreendedores se sentem na necessidade de receberem ajuda externa para identificarem o seu estilo de gestão. Em alguns casos eles se colocam ao lado dos seus funcionários, na tentativa de serem mais flexíveis e de escutarem mais a sua equipe, porém apresentam dificuldades para isso e se sentem receosos quando agem dessa forma.

Meu estilo de gestão eu não sei, acho que uma pessoa de fora tinha que ajudar a definir um pouco isso ai, tenho às vezes um pouco de dificuldade [...] então eu estou sempre insatisfeito com o trabalho do outro e com o meu também, me acho um pouco perfeccionista, meu estilo assim sempre tem que melhorar, sempre tem que mudar, sou um pouco chato (E-5).

Os empreendedores se sentem centralizadores por possuírem dificuldades em delegar tarefas e em confiar no funcionário, ficando sobrecarregados com atividades e ocasionando estresse. Contudo, eles reconhecem que isso é um defeito, mas possuem dificuldades em reverter esta questão, em alguns casos eles procuram a ajuda dos funcionários.

\footnotetext{
Eu tenho um grande defeito, eu tenho a tendência muito grande a ser centralizador, então eu tenho dificuldade em delegar funções, eu tenho dificuldade em confiar em algum colaborador, [...] eu tenho muita dificuldade de passar [...] eu tenho uma gestão muito centralizadora, eu tento mudar isso, mas tenho dificuldade muito grande em mudar, sei que é errado, sei que isso me sobrecarrega, sei que isso me estressa, mas eu tenho dificuldade em fazer isso (E-2).
}

Para definirem os seus modelos de gestão, os empreendedores se baseiam em modelos de empresas multinacionais norte-americanas como: McDonald, Google e Xerox, citadas pelos empreendedores durante as sessões, sendo estes modelos aprendidos ao longo de suas carreiras através das suas experiências profissionais, nas instituições de ensino e pela mídia e tidos por eles como exemplos de sucesso. Porém, eles reconhecem possuírem dificuldades em implantar nos seus próprios negócios o que eles aprenderam. Tal dificuldade pode ser explicada pelo fato desses modelos privilegiarem o trabalho prescrito, em relação ao trabalho real, com base em métodos padronizados e simplistas que desconsideram a complexidade da organização e das relações de trabalho, conforme abordado pela Psicodinâmica do Trabalho. 
Trabalhei numa Xerox cinco anos, e numa outra multinacional mais quinze anos, quando tento aplicar aquilo que eu fazia lá, porque ali tudo tinha que funcionar como um reloginho, tento fazer o que eu sei e aí não dá, não dá porque o tributário é fora de propósito, as exigências também nem se fala, a gente acaba entrando na enxurrada (E-8).

A dificuldade dos empreendedores de colocarem em prática os conhecimentos e modelos consagrados de outras organizações reforça a constatação de Dejours (2004) quanto às discrepâncias entre o trabalho prescrito. Para o autor, trabalhar é preencher a lacuna entre o prescrito e o real, ou seja, entre o maquinal e o humano. Assim o trabalho dos empreendedores se aproxima do real do trabalho, marcado por acontecimentos inesperados, e que implica em uma maior capacidade de mobilização da sua subjetividade e do uso da inteligência prática para se confrontar com o real do trabalho. Contudo, tal capacidade do empreendedor em se mobilizar, não significa obrigatoriamente em estar insensível aos sentimentos de medo, angústia e ansiedade frente ao risco do insucesso.

Pode-se constatar a partir da análise geral dos dados da pesquisa que as categorias predominantes na organização do trabalho dos empreendedores são: lidar com incertezas, lidar com a burocracia do Governo, lidar com o mercado de trabalho, cumprir com os padrões de mercado e com as exigências dos clientes, lidar com as cobranças dos funcionários, suportar a sobrecarga do trabalho, ser autogestor e multifuncional e se relacionar com funcionários, clientes, associações, sócios e parceiros.

\section{Conclusão}

Pode-se constatar que a organização do trabalho dos empreendedores se diferencia da maioria das profissões, dadas às incertezas vivenciadas por eles no cotidiano do seu trabalho, e se caracteriza por uma rotina de surpresas e de preparação, que, por sua vez, requer uma maior capacidade de planejamento e flexibilidade na realização das suas atividades. Em geral, os empreendedores possuem uma agenda diária cheia de compromissos, o que remete a uma carga de trabalho intensa. Contudo, eles possuem o poder de fazer modificações na organização do seu trabalho, em suas atividades e em seus horários, o que lhe permite uma maior liberdade e autonomia no seu cotidiano laboral.

Fica evidenciado, portanto, que os empreendedores possuem uma maior mobilização da inteligência prática no trabalho, resultando em uma maior predominância de vivências de prazer em decorrência da maior autonomia em planejar e organizar o seu trabalho e de executar as suas atividades. Apesar do poder dos empreendedores em planejar o seu próprio trabalho, eles nem sempre conseguem estabelecer uma rotina de trabalho.

Pode-se identificar que os empreendedores são, de certo modo, autogestores e, em geral, se encarregam de realizar uma ampla quantidade de tarefas que vão desde a solução de um problema técnico à negociação com fornecedores e clientes. Suas jornadas de trabalho não se limitam às dos seus funcionários. Constantemente eles levam trabalho para casa e realizam atividades, inclusive aos finais de semana. Apesar de tal situação remeter a uma perceptível sobrecarga de trabalho vivenciada, os empreendedores do coletivo de pesquisa alegaram não se sentirem sobrecarregados.
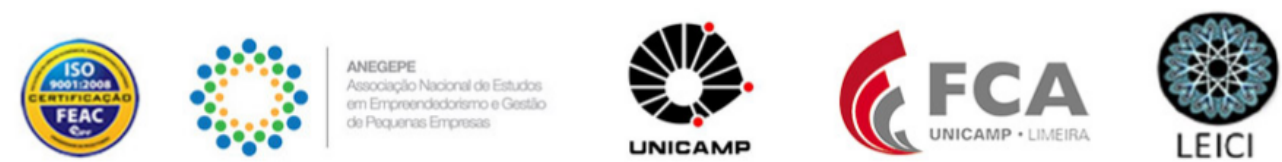
O que se pode constatar é que os empreendedores fazem uso de estratégias defensivas para suportar a sobrecarga de trabalho e não demonstrar fraqueza, especialmente diante dos seus funcionários, o que poderia ocasionar o enfraquecimento da mobilização do grupo e comprometer o sucesso da organização.

Quanto à organização do trabalho do empreendedor, constatou-se também certa particularidade no que se refere ao fato de terem que lidar com a pesada carga tributária e de se submeterem à burocracia imposta pelo Governo. Particularidade esta, não identificada em estudos relacionados a outras categorias de trabalhadores realizados por outros autores que fazem uso da abordagem da Psicodinâmica do Trabalho, mesmo em se tratando de profissões que se aproximam, como é o caso do grupo de trabalhadores informais de uma feira de importados, estudado por Morrone (2001).

A necessidade de dedicar tempo e esforço para compreender e lidar com a burocracia do Governo, eventualmente compromete a execução do trabalho do empreendedor. $\mathrm{O}$ resultado é uma situação conflituosa que mobiliza a sua subjetividade, causando-lhe angústia e sofrimento, sendo estes sentimentos reforçados pelo medo de ser flagrado descumprindo as normas e as leis impostas pelo Governo. Para lidar com tal situação, o empreendedor tende a adotar um excesso de zelo em especial no que se refere à ação da fiscalização. Assim, a ausência de uma hierarquia superior no caso do empreendedor, não o isenta, de certo modo, da total falta de obediência às normas e submissão aos mecanismos de controle.

Outras formas de controle que recaem sobre o trabalho do empreendedor, estão presentes nas exigências de qualidade dos produtos e serviços por parte dos clientes, buscando compatibilizar com as suas próprias intenções de metas e de planos criados para garantir a manutenção e o crescimento do negócio, frente aos padrões definidos pelo mercado e pela concorrência, o que nem sempre é possível. Tal fato também foi evidenciado nos estudos de Frese (2009).

As cobranças dos funcionários também se constituem em outra forma de controle sofrida pelo empreendedor. Os funcionários esperam que o empreendedor tome as decisões corretas, associando o sucesso do negócio à bem sucedida ação do empreendedor.

A comunicação com os seus funcionários se faz necessária para transmitir metas, definir prioridades, orientar na execução das tarefas, resolver problemas e debater questões da empresa. Contudo, o empreendedor nem sempre possui a habilidade e a disponibilidade de tempo para se comunicar com clareza. A qualidade da comunicação do empreendedor se agrava em decorrência da baixa formação educacional da mão de obra e dos diferentes níveis culturais.

Juntamente com a comunicação, outra unidade de análise que chama a atenção é o modo de gestão. No que se refere aos empreendedores, esta unidade está relacionada à sua capacidade de atuar em seu ambiente de trabalho e de liderar as pessoas e que, por sua vez, volta-se para as suas experiências vividas ao longo de suas vidas. Os empreendedores que participaram desta pesquisa relataram possuírem dificuldades em aplicar nos seus negócios os modelos aprendidos durante a sua formação profissional nas universidades e em suas experiências profissionais em empresas multinacionais como McDonald, Google e Xerox. Eles relataram não conhecerem com clareza o seu próprio estilo de gestão e que necessitam de ajuda para definir o modelo de gestão que melhor se enquadra à sua realidade organizacional.
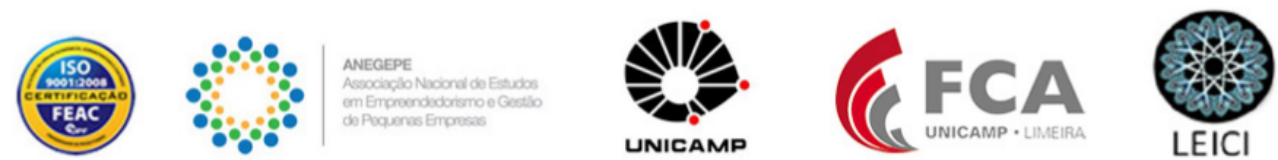
Tais dificuldades refletem nas suas relações com os seus funcionários e dificultam a comunicação com os mesmos.

As obrigações trabalhistas do país impostas ao empregador, resultam em expressiva desigualdade nas relações de trabalho entre este e seus funcionários e criam situações conflituosas, as quais os empreendedores precisam lidar. $\mathrm{Na}$ visão dos empreendedores participantes do coletivo de pesquisa, as leis trabalhistas do país são ultrapassadas e possibilitam que funcionários movidos pela "má-fé" sejam amparados pelas mesmas, como é o caso de funcionários que preferem permanecer sem assinar a carteira de trabalho para se beneficiarem do seguro desemprego ou que pedem para serem demitidos, ou criam situações para tal, com o intuito de receberem o acerto de contas e os benefícios do seguro desemprego. Aos funcionários são garantidos, também, os direitos trabalhistas como férias, décimo terceiro salário e licenças remuneradas, o que não ocorre no caso dos empreendedores.

Deste modo, lidar com os funcionários constitui uma dificuldade vivenciada pelo empreendedor e que, por sua vez, é agravada pelas leis trabalhistas do país e pela sua dificuldade em estabelecer um modelo de gestão coerente e de se comunicar de forma efetiva com os funcionários.

Em síntese, apesar dos empreendedores possuírem maior liberdade de atuação em seu trabalho, devido ao fato de estarem à frente da gestão dos negócios, eles não estão isentos de prescrições e controles. Condições impostas por elementos presentes no contexto externo à organização, como é o caso da burocracia do Governo e das exigências dos clientes, agravam ainda mais o contexto da organização do seu trabalho.

Conclui-se, portanto, que ao criar o seu próprio negócio, o empreendedor torna-se um agente ativo na modelagem tanto do seu próprio trabalho quanto da organização como um todo, o que lhe confere, de certo modo, uma maior liberdade e poder de determinar a divisão das tarefas e responsabilidades, bem como, de instituir o modelo de gestão que direcionará as relações de trabalho. Contudo, tal liberdade está limitada por elementos alheios à sua vontade como a burocracia do Governo, as relações sócio-profissionais estabelecidas com seus clientes, sócios e funcionários e o mercado de mão de obra.

\section{Referencial Teórico}

Bardin, L. (1977). Análise de Conteúdo. Lisboa, Portugal: Edições 70.

Chanlat, Jean-François (1995). Quais carreiras e para qual sociedade. Revista de Administração de Empresas, 35(6), 67-75.

Dejours, C. (1949). A loucura do trabalho, de Dejours, São Paulo: Editora Cortez.

Dejours, C. (1999). Conferências brasileiras: identidade, reconhecimento e transgressão no trabalho, São Paulo: Fundap.

Dejours, C. (2004). Subjetividade, trabalho e ação. Revista Produção, 14(3), 27-34.

Dejours, C. (2004). Da Psicopatologia à psicodinâmica do trabalho. S. Lancman \& L. I. Snelwer (Orgs.). Brasília: Paralelo 15.

Dejours, C., Abdoucheli, E., \& Jayet, C. (2010). Psicodinâmica do trabalho: contribuições da Escola Dejouriana à Análise da Relação Prazer, Sofrimento e Trabalho. Tradução de Maria Irene Stocco Betiol et al. São Paulo: Atlas.
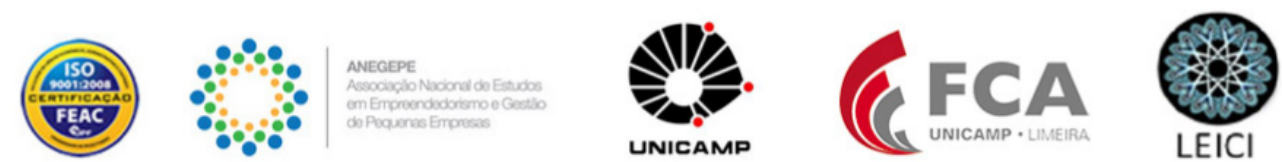
Dejours, C., \& Bègue, F. (2010). Suicídio e trabalho: o que fazer? Brasília, Paralelo 15.

De Vries, M. K. (1985). The dark side of entrepreneurship. Harvard Business Review, 160167.

Eckert, A., Mecca, M., Diasio, R., \& Caraiola, J. A. (2011). Psicologia do trabalho e empreendedorismo: uma análise de suas relações. XXXI Encontro Nacional de Engenharia de Produção. Enegep, Belo Horizonte, Minas Gerais, Brasil.

Ésther, A. B., Rodrigues, I. S., \& Freire, E. S. (2012). A identidade empreendedora no contexto de empresas de pequeno porte. Revista de Empreendedorismo e Gestão de Pequenas Empresas, 1(2).

Filion, Louis Jacques. (2000). Empreendedorismo e gerenciamento: processos distintos, porém complementares. RAE Light., 7(3), 2-7.

Frese, M. (2009). Rumo a uma psicologia do empreendedorismo: uma perspectiva da teoria ação. Fortaleza: Revista de Psicologia, 1(1), 9-32.

Guimarães, L. O., \& Siqueira, M. M. (2010). Empreendedorismo: à procura de uma abordagem de pesquisa. Coleção Empreendedorismo e Estratégia. Curitiba: Editora PUCPR.

Machado, H. V. (1999). Tendências do comportamento gerencial da mulher empreendedora. Anais do Enanpad, Rio de Janeiro, RJ, Brasil.

Mendes, A. M., \& Araújo, L. K. R. (2011). Clínica psicodinâmica do trabalho: práticas brasileiras. Brasília: Ex-líbris.

Minello, I., Scherer, L., Perlin, A. P., Alves, L. C., \& Huezo, M. (2011). Comportamento e tipologia do empreendedor diante do insucesso empresarial. XXXV Encontro da Anpad, Osasco, São Paulo, Brasil.

Scherer, L., \& Minello, I. (2014). Características do comportamento empreendedor durante o insucesso empresarial. Revista Pensamento Contemporâneo em Administração, 8(3).

Morrone, C. F. (2001). "Só para não ficar desempregado" - resignificando o sofrimento psíquico no trabalho: estudo com trabalhadores em atividades informais. Dissertação de Mestrado em Psicologia, Universidade de Brasília, Brasília, Brasil.

Nassif, V. M. J., Nassif, W., Piscopo, M. R., \& Lima, E. O. E o que dizem os empreendedores sobre a criação, sobrevivência e desenvolvimento de suas empresas? Um estudo exploratório. Revista Brasileira de Gestão e Desenvolvimento Regional, 11(2).

Paiva JR, F. G. (2004). O empreendedorismo na ação de empreender: uma análise sob o enfoque da fenomenologia sociológica de Alfred Schütz. Tese de Doutorado em Administração, Universidade Federal de Minas Gerais, Belo Horizonte.

Paulino, A. D., \& Rossi, S. M. M. (2003). Um estudo de caso sobre o perfil empreendedor: características e traços de personalidade empreendedora. EGEPE, Brasília. pp. 205-220.

Silva, W. A. C., Fonseca, R. A., \& Araújo, E. A. T. (2015). Comportamento empreendedor e trajetória empresarial de fundadores de MPES em Barão de Coais/MG. Revista de Empreendedorismo e Gestão de Pequenos Negócios, 4(2).

Taylor, F. W. (1995). Princípios da administração científica. São Paulo: Atlas. 